IZA DP No. 4529

Mother or Child?

Intra-Household Redistribution under

Gender-Asymmetric Altruism

Indraneel Dasgupta

October 2009 


\title{
Mother or Child? Intra-Household Redistribution under Gender-Asymmetric Altruism
}

\author{
Indraneel Dasgupta \\ Durham University \\ and IZA
}

\section{Discussion Paper No. 4529 \\ October 2009}

\author{
IZA \\ P.O. Box 7240 \\ 53072 Bonn \\ Germany \\ Phone: +49-228-3894-0 \\ Fax: +49-228-3894-180 \\ E-mail: iza@iza.org
}

Any opinions expressed here are those of the author(s) and not those of IZA. Research published in this series may include views on policy, but the institute itself takes no institutional policy positions.

The Institute for the Study of Labor (IZA) in Bonn is a local and virtual international research center and a place of communication between science, politics and business. IZA is an independent nonprofit organization supported by Deutsche Post Foundation. The center is associated with the University of Bonn and offers a stimulating research environment through its international network, workshops and conferences, data service, project support, research visits and doctoral program. IZA engages in (i) original and internationally competitive research in all fields of labor economics, (ii) development of policy concepts, and (iii) dissemination of research results and concepts to the interested public.

IZA Discussion Papers often represent preliminary work and are circulated to encourage discussion. Citation of such a paper should account for its provisional character. A revised version may be available directly from the author. 
IZA Discussion Paper No. 4529

October 2009

\section{ABSTRACT \\ Mother or Child? Intra-Household Redistribution under Gender-Asymmetric Altruism*}

In developing societies, social norms typically ascribe differential weights to paternal, maternal and communal (or state) contributions to children's expenses. Individuals internalize these valuations. I examine a Cournot model of voluntary contribution to children's goods in a two-adult household, where both spouses may have marginal rates of substitution across paternal, maternal and communal contributions that differ from unity. I show that a conflict may exist between the interests of parents and those of children. Depending on the marginal rate of substitution between paternal and maternal contributions, a lump-sum redistribution from fathers to mothers may make children better off, but both parents worse off, or vice versa. Additional public contribution funded by a lump-sum tax on either parent may make children better off, but at the cost of both parents. Thus, proposals to redistribute income from fathers to mothers need to take into account socially valorized gendered asymmetries in parental roles. Furthermore, there may exist a conflict, instead of congruence, between women and their children.

JEL Classification: $\quad \mathrm{H} 23, \mathrm{H} 31, \mathrm{I38}, \mathrm{J} 16$

Keywords: intra-household distribution, social norms, domestic public good, redistribution

Corresponding author:

Indraneel Dasgupta

Dept. of Economics

The Business School

Durham University

23-26 Old Elvet

Durham DH1 3HY

United Kingdom

E-mail: indraneel.dasgupta@durham.ac.uk

\footnotetext{
* I thank Simon Appleton, Anita Dixit and seminar audiences at ISI Delhi, ISI Kolkata, University of Kolkata, Nottingham and the UNU-WIDER Conference on Gender and Food Security, Accra for clarifying conversations.
} 


\section{Introduction}

There exists a widespread presumption in the developmental policy discourse that redistribution of resources from husbands to wives is likely to improve the well-being of both married women and their children, and, furthermore, that there is a natural congruence of interests between mothers and their children, as against those of fathers. This presumption underlies the large-scale introduction of policies that seek to redistribute income from husbands to wives in many developing countries. ${ }^{1}$ Yet the theoretical underpinnings of this presumption, typically derived from overly simple partial equilibrium models, are somewhat shaky. Attempts to redistribute resources from husbands to wives can in fact end up making women actually worse off. This paradoxical consequence may occur, for example, when labor markets exhibit a two-tiered structure, as is typically the case in developing countries (Dasgupta (2000)), or when the redistributive mechanism reduces male incentives to work (Dasgupta (2001)). Furthermore, the interests of mothers and their children might actually be in conflict: redistribution from fathers to mothers might improve the welfare of both children and their fathers, but, ironically, make the mothers themselves worse off. Thus, the welfare consequences of policy attempts to redistribute income from men to their wives can be far more complicated, and perverse, than is commonly acknowledged.

A closer, and more nuanced, examination of the theoretical foundations underlying policy interventions to redistribute resources from husbands to wives, and their connection to children's welfare, is therefore of critical importance. The purpose of this paper is to offer such an examination that encompasses a hitherto neglected aspect, viz., culturally constructed differences in the valuation of paternal, maternal and communal (or public) contributions to children's consumption. I show that internalization of such differences by parents can have critical consequences for attempts to redistribute resources from fathers to mothers. Interests of mothers may be aligned with those of their husbands, but in direct conflict with those of their children. Redistribution may improve the well-being of children at the cost of both parents, or vice versa, depending on the exact nature of gendered differences in valuation of parental contributions. Likewise, greater communal contribution funded by a lump-sum tax on either parent can make children better off, but both parents worse off. These conflicts are basic, in that they arise even in a simple partial equilibrium model of intra-household allocation with exogenous labor supply, which completely abstracts from labor market distortions and focuses on balanced-budget lump-

\footnotetext{
1 While my policy focus is on developing countries, this presumption is quite prevalent in developed countries as well. Changes in the U.K. child benefit scheme in the late '70s, which replaced a tax deduction for the father by a cash payment to the mother, constitute a particularly interesting example in a developed country context. This led a redistribution of about $8 \%$ of average male earnings from fathers to mothers (see Lundberg et al. (1997)). Routine examples of such policy interventions in developing countries in favor of women include changes in inheritance laws and property rights, gender-based hiring quotas (or, more generally, affirmative action programs) in the labor market, training, marketing support and subsidized lending programs targeted towards women. Recently, India has even started experimenting with lower income tax rates for women.
} 
sum redistributions. Thus, the welfare consequences of attempts at redistributing income from one spouse to another cannot be predicted without taking into account the exact nature of culturally constructed gendered differences in the valuation of parental and communal contributions prevalent in a society.

In most, arguably all, developing societies, considerable normative emphasis is placed on the duty of parents to contribute to their children's well-being. As a parent, one's social standing is to a significant extent dependent on the extent to which the individual is perceived by others as fulfilling this duty. Children are taught to valorize the ethics of self-sacrifice for the sake of one's own children from a very early age. Consequently, individuals typically come to internalize such a parental duty ethic before becoming parents. However, there are systematic gender-specific differences in the social construction of this parental duty ethic. In some societies, child bearing is considered constitutive of a woman's identity, but providing for the children beyond early infancy is considered primarily the responsibility of the father. $^{2}$ In other societies, child bearing and providing for them till they attain adulthood are both considered the primary normative responsibility of the mother. If individuals internalize these gendered asymmetries in social valorization of parental responsibility, they may intuitively be expected to value mothers' contributions and fathers' contributions differently when they themselves become parents, even though the contributions, being materially indistinguishable, impact identically on children's well-being in an objective sense. ${ }^{3}$ In the first case, both parents might be expected to receive some psychic benefit if the father provides a greater proportion of children's consumption. The very act of greater paternal contribution might confer some direct benefit on the father, from a private sense of satisfaction and selfesteem at having conformed better to the socially valorized division of domestic responsibilities, and/or from the collective respect such conformity might command from others. Assuming, reasonably, that men and women internalize identical social values, for mothers, having to provide a greater proportion of children's expenses would generate a psychic loss, since women would resent having to perform a duty they do not consider rightly theirs, and evaluate their marriages according to the extent to which their husbands conform to the socially prescribed paternal responsibilities. In the second case, conversely, both parents might receive a psychic benefit from the mother's act of contributing a higher proportion of

2 For illustrative discussions of such norms of differential responsibility and their connections to differences in fertility demands between husbands and wives in the African context, see Fapohunda and Todaro (1988), Boserup (1985) and Caldwell and Caldwell (1978).

${ }^{3}$ Children may conceivably perceive their own well-being through such a normative lens. In discussing children's welfare, my focus however is on the objective conditions, i.e. material inputs, facilitating children's development, not their own perception of their well-being. Such a 'paternalistic' approach to children's well-being, involving assessment in terms of criteria that are independent of (and possibly contrary to) juvenile preferences, is of course routine in social policy. Governments invariably restrict children's legal rights to buy, sell, leave school, get married, or participate in the political process. Governments also routinely evaluate children's well-being independently of parental perception of such well-being, consequently restricting parents' rights over children. I shall accordingly identify children's welfare with their material consumption, not the sources of such consumption. 
children's consumption. In either case, both husbands and wives would perceive their spouse's contributions to children's consumption as imperfect substitutes for their own, even though they are materially indistinguishable. ${ }^{4}$ Thus, while an additional dollar spent on children's goods has the same material impact on children's welfare regardless of its source, the identity of its contributor would have a bearing on the self-perception of well-being on part of both parents, and, consequently, their welfare. What impact would a balanced-budget lump-sum redistribution of income from husbands to wives have on the welfare of different household members in such a context?

An analogous question arises as soon as one notes that, typically, parents are not the only major source of contributions to child-rearing. The external 'community' within which the family is embedded usually contributes significantly to the process as well. Most obviously, the state typically provides direct support in the form of subsidized or free provision of health and education facilities for children. In many countries, the government also provides nutritional supplements to children through school meal programs. But support is not confined to the formal state apparatus. Looser forms of collectivity such as the village, the clan or the extended family also contribute to the rearing of children born to couples embedded in such collectivity. ${ }^{5}$ Yet 'communal' contribution, in this inclusive sense of both governmental and identity-group support, is, arguably, not perceived as normatively indistinguishable from parental support. Typically, social norms appear to valorize parental contribution over such communal contribution, in the sense that the primary responsibility for looking after children is seen as lying with the parents. To the extent that parents internalize these norms, they may be expected to value a dollar of own contribution to children's upkeep more than a dollar of communal contribution. ${ }^{6}$ What impact then, would an increase in communal contribution, funded by a balanced-budget lump-sum tax on either parent, have on the distribution of consumption (and thus welfare) inside the household?

In traditional analysis, where husbands and wives are assumed to consider each other's, and external (i.e. communal), contributions perfect substitutes for their own, the answer, typically, is 'none'. Non-cooperative models of voluntary contributions to children's goods predict that, in case of a

4 That individuals can receive a 'warm glow' directly from the act of giving, and thus value own contributions differently from contributions by others, even when they are materially identical, has been widely acknowledged in the general theoretical and empirical literature on voluntary giving. See, for example, Dasgupta and Kanbur $(2007 a, b)$ and the references therein. However, this literature has not addressed the implications of possible systematic differences in the extent of such warm glow, which is my focus.

${ }^{5}$ Village communities, clan and extended family networks in poor countries do often play an important, systematic role in the nurturing of their juvenile members. Such communal nurturing appears important for the future stability of communal identities. It may thus be seen as analogous to the oft-noted role played by such collectivities in the management of more material forms of joint property resources (e.g. Baland and Platteau (2003), Ostrom (1990)).

${ }^{6}$ This is analogous to the observation, routinely made in the context of welfare transfers, that individuals may feel stigmatized or 'ashamed' when receiving 'charitable' transfers and, consequently, value a dollar of 'earned' income more than a dollar of welfare payment (Breunig and Dasgupta (2003, 2002), Levedahl (1995) and Moffitt (1983)). 
redistribution from the husband to the wife, the former would reduce his contribution by exactly the amount lost, while the latter would compensate exactly by increasing hers by the same amount. Consequently, all household members would find their consumption, and thus, their welfare, unchanged. ${ }^{7}$ An increase in communal spending on children funded by a balanced-budget lump-sum tax on either parent would likewise leave consumption bundles invariant. However, in our expanded context where individuals consider their spouses', and other people's, contributions imperfect substitutes for their own, a priori, the answer is not at all intuitively clear. One may expect the husband to cut down his contribution to children's expenses by some amount, say $x$, in response to a loss of one dollar of his own income. Thus, when the wife gains one dollar of own income, whether she perceives herself as better off would depend on her valuation of the cutback in children's spending on part of her husband. As discussed earlier, depending on internalized social norms, she may perceive $x$ dollars of contribution by her husband as better or worse than $x$ dollars contributed from her own earnings. Consequently, the redistribution need not necessarily make the wife better off in her own perception. The impact on total provision of children's goods, and thus, their welfare, becomes likewise intuitively non-obvious. The problem is analogous when both parents value communal contributions less than parental contribution.

The objective of this paper therefore is to address these questions. I set up a Cournot model of voluntary contributions to children's goods in a two-adult household, where parental incomes and communal contribution are exogenously given, and both spouses may have marginal rates of substitution between paternal, maternal and communal contributions that differ from unity. I assume that social norms are internalized in a gender-neutral manner, so that husbands and wives have identical relative valuations for paternal, maternal and communal contributions. I consider the welfare implications of a marginal (balanced-budget) redistribution from the husband to the wife when both spouses contribute positive amounts to children's consumption. I also consider the intra-household distributive consequences of a marginal rise in communal provision, funded by a (balanced-budget) lump-sum tax on either spouse. I show that a conflict may exist between the interests of parents and those of their children. When maternal contributions are valued less than paternal contributions, redistribution from the husband to the wife increases total spending on children. Thus, children are better off. However, despite

\footnotetext{
7 See, for example, Dasgupta (2001) for an expanded discussion. Contributions in this tradition include Breunig and Dasgupta (2005), Chen and Woolley (2001), Dasgupta (2001), Carter and Katz (1997), Konrad and Lommerud (1995), Kanbur (1995) and Lundberg and Pollak (1993). Costs associated with negotiating as well as enforcing intra-household agreements intuitively motivate the choice of the non-cooperative model over the cooperative bargaining framework. See Konrad and Lommerud (1995) for an extensive justification along these lines. Udry (1996) offers evidence against the assumption, central to cooperative bargaining models, of efficient intra-household decision-making. The phenomenon of domestic violence common in (but certainly not exclusive to) developing societies also intuitively militates against the assumption of efficient intra-household decision-making. The redistribution would evidently be non-neutral in the analytically trivial, and empirically implausible, case of a corner solution: it would make both the wife and the children better off if the husband was spending nothing on children's goods initially, whereas it would make the children worse off if the wife was contributing nothing initially.
} 
total household income remaining invariant, both parents are worse off; in terms of their private consumption as well as welfare. The opposite is true when paternal contributions are valued less than maternal contributions. If parental contributions are valued more than communal contributions, a rise in communal provision funded by a lump-sum tax on either parent makes children better off, but both parents worse off. Thus, contrary to the common perception, there may exist a unity of interests between parents, and a conflict between parents and their children. ${ }^{8}$ Social policy formulation may need to take explicit cognizance of this conflict. The impact, on children's well-being, of a relative rise in maternal incomes cannot be predicted without taking into account relative social valuations of paternal, maternal and communal contributions. Furthermore, redistributions that can acquire broad political support may be precisely those that hurt children: greater communal contribution may dominate greater parental provision from the children's perspective, but would nevertheless be opposed by their parents.

Section 2 sets up the basic model. Section 3 presents the central results. I conclude in Section 4.

\section{The Model}

Consider a household consisting of two parents, M and F, and children. Each parent derives utility from a private good and a (composite) good consumed by children, some of which may be provided by the community, $\mathfrak{I}$. For any parent $k \in\{M, F\}$, let $x_{k}$ denote private consumption; let $y$ denote the total amount of the children's good, while $y_{k}, y_{-k}$ and $T$ will denote the amounts of the children's good provided, respectively, by $k$, the other parent and $\mathfrak{I}$ (i.e., the community); $y \equiv y_{k}+y_{-k}+T$. Parent $k$ has exogenously given own income $I_{k}>0 ; T \geq 0$. Given communal provision for children (T), M and F simultaneously choose the allocation of their income between private consumption and children's

8 It is this conflict of interest between non-contributors (children) and contributors (parents) which sharply demarcates my analysis from earlier analogous contributions to the general literature on voluntary contributions to a public good. My analysis has a structural analogy with models of voluntary contribution to a pure public good where contributors differ in terms of the marginal productivity of their contributions to the public good (e.g. Ihori (1996), Konrad and Lommerund (1995)). However, objective differences in productivity and subjective differences in valuation intuitively address very different phenomena. Furthermore, in the former case, a lump-sum income transfer from a less productive contributor to a more productive one makes both parties better off, by increasing total provision of the public good. In my model, a lump-sum redistribution from the low valuation parent to the high valuation one similarly makes both parents better off, but, in sharp contrast, reduces the material amount of the intra-household public good, thereby making children worse off. Thus, my focus on differences in subjective valuation of contributions that are materially identical leads to predictions about the equilibrium material magnitude of the domestic public good that directly contradict the predictions of a model of pure public good provision with differing marginal productivities. Ihori (1992) considers an impure public goods model, but focuses on the welfare implications of income redistribution exclusively for contributors. Non-contributors do not appear in that analysis. My application of this general framework differs from Ihori (1992) both in my specific intra-household focus and in my explicit concentration on how income redistribution among contributors (parents) impacts on the welfare of noncontributors (children). 
expenditure. $^{9}$ Thus, intra-household allocation is modeled as a Cournot game of voluntary contributions to a domestic public good, interpreted as children's consumption. ${ }^{10}$

For $k \in\{M, F\}$, preferences are given by a strictly quasi-concave and twice-differentiable utility function $u^{k}\left(x_{k}, B_{k}\right)$, where $B_{k} \equiv y_{k}+\theta_{k} y_{-k}+\tau_{k} T ; \theta_{k}, \tau_{k}>0$. Thus, I allow (without assuming) the possibility that paternal and maternal preferences may differ: $u^{M}, u^{F}$ need not exhibit identical functional forms. Notice in particular that I permit the mother to (possibly but not necessarily) put a higher weight on children's consumption relative to the father. ${ }^{11}$ The parameter $\theta_{k}$ measures the extent to which parent $k$ considers her own contribution to children's expenses a substitute for her spouse's contribution. It is the marginal rate of substitution between the other parent's contribution and her own. Given her private consumption and communal provision, a unit increase in the other parent's contribution would leave $k$ 's utility unchanged if, and only if, her own contribution were to be reduced by the amount $\theta_{k}$. Notice that preferences can be represented by $u^{k}\left(x_{k}, y-\left(1-\theta_{k}\right) y_{-k}-\left(1-\tau_{k}\right) T\right)$. Thus, given private consumption and total children's consumption, a substitution of a unit of her spouse's contribution by one additional unit of her own contribution changes $k$ 's utility by $\left(1-\theta_{k}\right) \frac{\partial u^{k}}{\partial y}$. Analogously, a substitution of a unit of communal provision by one unit of own contribution leads to a change of $\left(1-\tau_{k}\right) \frac{\partial u^{k}}{\partial y}$. The terms $\left(1-\theta_{k}\right)$ and $\left(1-\tau_{k}\right)$ thus measure the extent of $k$ 's direct personal benefit from the act of giving per se. I shall assume that men and women internalize identical social norms regarding the relative valuation of paternal, maternal and communal contributions to children's expenses.

A1. (i) $\theta_{F}=\theta_{M}^{-1}$; and (ii) $\tau_{F}=\tau_{M} \theta_{M}{ }^{-1}$.

In traditional formulations, parents are assumed to value all contributions equally, so that, given private consumption, only the total amount of children's consumption is perceived as relevant for their welfare.

${ }^{9}$ One could alternately interpret the model in terms of allocating a given endowment of labor between market work and child-rearing. So long as child-rearing labor by parents can be substituted by purchased goods, including domestic services, it does not matter whether parental contribution consists of purchased goods or time. For a discussion in the general context of voluntary contributions to public goods, see Dasgupta and Kanbur (2005).

${ }^{10}$ Intra-household interaction may also be modeled as a Stackelberg game without affecting my basic conclusions.

11 More formally, $\frac{\partial u^{F}}{\partial x_{F}} / \frac{\partial u^{F}}{\partial B_{F}}$ may be lower than $\frac{\partial u^{M}}{\partial x_{M}} / \frac{\partial u^{M}}{\partial B_{M}}$. 
This, the so-called 'pure' public good case, is a special case in my analysis, where $\theta_{M}=\tau_{M}=1 .{ }^{12}$ In this case, agents do not perceive any utility gain from contributing as such. The public good may also be 'impure': agents may perceive, and value, paternal, maternal and communal contributions differently. In this case, where $\theta_{M} \neq 1$, or $\tau_{M} \neq 1$, or both, the total amount of the public good and the distribution of contributions both become relevant for a parent's perception of her well-being.

When $\theta_{M}, \tau_{M}<1$, given total consumption of every good, both $\mathrm{M}$ and $\mathrm{F}$ receive some additional benefit if $\mathrm{M}$ provides a greater proportion of the public good. Thus, the act of contributing itself provides some direct personal benefit to $\mathrm{M}$, as in standard models of 'warm glow' giving (e.g. Dasgupta and Kanbur (2007a and 2007b), Cornes and Sandler (1994) and Andreoni (1990)). However, unlike such models, this 'warm glow' is not confined to the contributor alone. In my context, the natural interpretation of this benefit is in terms of both the personal satisfaction and the social esteem acquired by virtue of being in a marriage where the division of responsibilities conforms to socially prescribed and valorized gender roles, perceived as natural 'duties' both by oneself and others. Thus, $\theta_{M}, \tau_{M}<1$ models the case where both men and women perceive it the natural, normatively prescribed, duty of men (and not their wives, nor the community at large) to be the principal provider for their children, and evaluate marriages according to the extent to which the husband fulfills this role. Consequently, not fulfilling or conforming to this role generates a feeling of guilt, shame and self-loathing for men, as well as a loss of social esteem. In this case, the wife also suffers a welfare loss if her husband's contribution is replaced either by her own contribution or by communal contribution. I interpret the first case in terms of a sense of resentment at: (i) having to perform a role that one does not perceive as one's natural duty, and (ii) being considered an object of pity by others for that reason. In the second case, the intuitive interpretation is that of feelings of guilt, shame and resentment at having to depend on 'charity' for the up-keep of one's own children, instead of one’s husband. Analogously, I interpret $\theta_{M}>1$ as modeling the case where providing for children is considered primarily the responsibility of their mothers.

For notational simplicity, I shall assume all prices to be unity. Then, for all $k \in\{M, F\}$, parent k's optimization problem is:

$$
\begin{aligned}
& \text { Max } u^{k}\left(x_{k}, B_{k}\right) \text { subject to: } \\
& x_{k}, B_{k} \\
& x_{k}+B_{k}=I_{k}+\theta_{k} y_{-k}+\tau_{k} T ; \\
& 0 \leq x_{k} \leq I_{k} .
\end{aligned}
$$

12 The earlier literature on non-cooperative models of intra-household decision-making, cited in footnote 7 , concentrates exclusively on this pure public good case. 
Equation (1) is the budget constraint; (2) is simply the requirement that no parent can divert the other's, nor the community's, contribution towards children's expenses to her own private consumption.

The solution to the optimization problem above, subject to the budget constraint (1) alone, yields, in the standard way, the unrestricted demand functions:

$$
\begin{aligned}
& x_{k}=X^{k}\left(I_{k}+\theta_{k} y_{-k}+\tau_{k} T\right), \\
& B_{k}=B^{k}\left(I_{k}+\theta_{k} y_{-k}+\tau_{k} T\right) .
\end{aligned}
$$

Notice that, by A1, we must have:

$$
B_{k} \equiv \theta_{k} B_{-k} .
$$

I shall assume that both goods are normal for either parent. Thus, noting (3), I assume the following.

$$
\text { A2. For all } k \in\{M, F\}, \frac{\partial B^{k}(.)}{\partial I_{k}} \in(0,1) \text {. }
$$

A2 suffices to ensure the existence and uniqueness of the Nash equilibrium. ${ }^{13}$ I shall assume that both parents contribute positive amounts towards children's expenses in the Nash equilibrium, so that (2) does not bind. ${ }^{14}$ Hence, the equation system given by (3)-(4) must hold in the Nash equilibrium. The solution to the equation pair for the unrestricted private demand functions specified by (3) yields the Nash equilibrium levels of private parental consumption, and thus parental contributions, given the parameters of the model $I_{M}, I_{F}, T, \theta_{M}$ and $\tau_{M}$ (recall A1).

The obvious (money metric) measure of children's welfare is their total consumption in the Nash equilibrium (recall footnote 3). I now specify an analogous measure of parental welfare. For $k \in\{M, F\}$, define:

$$
r_{k}^{*} \equiv V_{k}^{-1}\left(u\left(x_{k}^{*}, y_{k}^{*}+\theta_{k} y_{-k}^{*}+\tau_{k} T\right)\right),
$$

where $V_{k}$ is the indirect utility function corresponding to $u^{k}$ and the superscript $*$ represents the Nash equilibrium value of the relevant variable. Thus, $r_{k}^{*}$ is parent $k$ 's real income, or equivalent income, in the Nash equilibrium. It is the amount of money that $k$ would need to achieve the same utility that she actually receives in the equilibrium, if, for some reason, both the other parent and the community were to stop contributing entirely. Thus, the equivalent variation $\left[r_{k}^{*}-I_{k}\right]$ provides a money metric measure of

\footnotetext{
${ }^{13}$ See, for example, Andreoni (1990).

${ }^{14}$ It is easy to see that, given the parameters $\theta_{M}, \tau_{M}, T$, there must exist configurations of $I_{M}, I_{F}$ where both parents are necessarily contributory in the Nash equilibrium.
} 
the benefit $k$ receives by virtue of the contribution the other parent and the community make to the domestic public good: it measures the monetary equivalent of $k$ 's gain from being in the relationship and in the community. Evidently, $k$ would be better off in some equilibrium rather than another if, and only if, her real income is higher in the former. Since, by assumption, (2) does not bind, (1) and (6) imply:

$$
r_{k}^{*}=I_{k}+\theta_{k} y_{-k}^{*}+\tau_{k} T
$$

Real incomes thus provide the natural money-metric measure of equilibrium parental welfare. Notice however that, by A2 and (7), parental private consumption is a positive function of real income. Thus, one can equivalently identify parental welfare with parental private consumption, instead of real income. ${ }^{15}$

At this stage, it is useful to note the consequences of considering others' contributions to childrearing an imperfect substitute for one's own, a prescriptive social norm that seems to be pervasive, especially (but certainly not exclusively) in traditional societies.

Observation 1. Let $A 1$ and $A 2$ hold. Then:

(i) given $\tau_{M}$, a rise in $\theta_{M}$ must increase paternal private consumption and real income, while reducing maternal private consumption and real income;

(ii) given $\theta_{M}$, a rise in $\tau_{M}$ must increase private consumption and real income of both parents, while reducing children's consumption.

Proof: See the Appendix.

By Observation 1, if parents come to consider M's contribution a better substitute for F's ( $\theta_{M}$ falls), F must reduce her own contribution, while her husband must increase his. Consequently, F's private consumption and her real income must both rise, while M's private consumption and real income must both fall. Thus, such a shift would improve the well-being of F, at the cost of M. Note that the aggregate impact on children's consumption, and thus their welfare, is indeterminate. Later in this section I provide an example where a fall in $\theta_{M}$ actually reduces the welfare of children. Contributions by both parents must rise if communal contribution comes to be perceived as a worse substitute for paternal contribution (i.e., if $\tau_{M}$ falls). This would improve children's consumption, but reduce private consumption (and real income) of both parents. Thus, social norms, in order to be optimal for children, must necessarily involve over-valorization of paternal contribution relative to communal contribution (i.e. $\tau_{M}<1$ ). Equal

${ }^{15}$ One may therefore focus simply on changes in parental private consumption as qualitative indicators of changes in parental welfare. Evidently, this qualitative equivalence breaks down when parents are non-contributory. 
valuation of paternal and maternal contributions $\left(\theta_{M}=1\right)$ does not, in general, maximize children's consumption. Observation 1 therefore leads one to speculate that normative under-valuation of communal contribution to child-rearing relative to parental contribution, and differential valorization of paternal and maternal contributions, may both serve to enhance children's survival prospects, and thus the long-term population growth rate. These functions may conceivably provide one clue to the pervasive presence of such norms.

Notice furthermore that low values of $\theta_{F}$ benefit fathers (and, possibly, children) at the cost of mothers. This suggests a possible contradiction at the heart of patriarchal values. Intuitively, a high value of $\theta_{F}$ (i.e., $\theta_{F}>1$ ) would appear to be commensurate with a general social over-valuation of the importance of men. Yet such over-valuation also turns out to be costly for men. Conversely, a low value of $\theta_{F}$ would benefit men, but might be difficult to square with inflated notions of male importance. In practice, one often observes an uneasy co-existence of cultural notions of male superiority with intense valorization of an ethics of maternal self-sacrifice in strongly patriarchal societies. The cult of the Madonna in Latin countries, and the celebration of the mother-goddess in India, both appear to suggest themselves as immediate examples. Observation 1 offers a possible interpretation for this tension. It follows that societies may under-value paternal contributions despite being strongly patriarchal.

Societies however routinely attempt to critique extant social norms during periods of rapid economic transformation. Observation 1 suggests that attempts to alter social values in ways that lead to women becoming willing to trade off a greater amount of their own contribution, in exchange for an additional unit of their husbands' contribution, may also shift the intra-household distribution of resources, and thus, welfare, towards women. Encouragement of such alteration in social values (intuitively, cultural contestation of a prevalent, 'Madonna' or 'Devi' ethic of maternal self-sacrifice, which undervalues paternal contribution) would thus be reasonable if the objective is to increase private consumption of mothers. Attempts at social engineering via normative over-valorization of paternal contribution relative to maternal contribution (i.e., lowering of $\theta_{M}$ below unity), may therefore, somewhat paradoxically, benefit mothers. This shift would however come at the cost of reduced consumption by fathers and, possibly but not necessarily, their children. Analogously, social norms that emphasize one's parental duty to provide for one's own children, and stigmatize recourse to communal support, may serve to increase the consumption of children while reducing that of parents. Thus, cultural celebration of such a parental duty ethic (which serves to stigmatize recourse to, and thereby undervalue, communal contribution) would be reasonable if the objective is to increase children's consumption. In sum, changes in relative social valuations are not distribution-neutral between parents and their children, nor, indeed, between mothers and fathers. 


\section{An example: identical and homothetic preferences}

It is useful to illustrate the general model with a simple example at this stage. Consider the special case where the utility functions $u^{M}$ and $u^{F}$ are identical and homothetic. Then, in the Nash equilibrium,

$$
x_{k}=\beta\left(I_{k}+\theta_{k} y_{-k}+\tau_{k} T\right) ;
$$

where $\beta \in(0,1)$ is the preference parameter, reflecting the relative weight put on private consumption. Together, (1) and (8) imply, in the Nash equilibrium, for all $k \in\{M, F\}$ :

$$
y_{k}=I_{k}(1-\beta)-\beta\left(\theta_{k} y_{-k}+\tau_{k} T\right) .
$$

Using (9) and A1, I get closed form solutions:

$$
\begin{aligned}
& y_{F}^{*}=\frac{\left[I_{F}-I_{M} \theta_{F} \beta\right](1-\beta)-\left(\tau_{F}-\tau_{M} \beta \theta_{F}\right) \beta T}{\left(1-\beta^{2} \theta_{M} \theta_{F}\right)}=\frac{\left[I_{F}-I_{M} \theta_{F} \beta\right] \theta_{F}-\tau_{M} \theta_{F}^{2} \beta T}{(1+\beta) \theta_{F}} . \\
& y_{M}^{*}=\frac{\left[I_{M}-I_{F} \theta_{M} \beta\right](1-\beta)-\left(\tau_{M}-\tau_{F} \beta \theta_{M}\right) \beta T}{\left(1-\beta^{2} \theta_{M} \theta_{F}\right)}=\frac{\left[I_{M} \theta_{F}-I_{F} \beta\right]-\tau_{M} \theta_{F} \beta T}{(1+\beta) \theta_{F}} .
\end{aligned}
$$

Using (10)-(11), I then get the Nash equilibrium consumption levels of all goods.

$$
\begin{aligned}
y^{*} & =\frac{\left[I_{M}\left(1-\beta \theta_{F}\right)+I_{F}\left(1-\beta \theta_{F}^{-1}\right)\right\rfloor+T\left[(1+\beta)-\left(1+\theta_{F}\right) \tau_{M} \beta\right]}{(1+\beta)} \\
x_{F}^{*} & =\frac{\left[I_{F}+I_{M} \theta_{F}+\tau_{M} \theta_{F} T\right] \beta}{(1+\beta)}, \\
x_{M}^{*} & =\frac{\left[I_{M}+I_{F} \theta_{F}^{-1}+\tau_{M} T\right] \beta}{(1+\beta)}
\end{aligned}
$$

Furthermore, (7), (10) and (11) yield parental real incomes:

$$
\begin{aligned}
r_{F}^{*} & =\frac{I_{F}+I_{M} \theta_{F}+\tau_{M} \theta_{F} T}{(1+\beta)} . \\
r_{M}^{*} & =\frac{I_{M}+I_{F} \theta_{F}{ }^{-1}+\tau_{M} T}{(1+\beta)} .
\end{aligned}
$$

Equations (12), (15) and (16) provide money-metric measures of welfare for children, $\mathrm{F}$ and $\mathrm{M}$, respectively. Notice that, when fathers earn more than mothers $\left(I_{M}>I_{F}\right),(12)$ implies the existence of some $\vec{\theta}_{M}>1$ such that children's consumption falls with any fall in $\theta_{M}$ when $\theta_{M} \leq \vec{\theta}_{M}$. Thus, children's consumption is maximized at some value of $\theta_{M}$ greater than unity. Hence, a rise in the 
relative valuation of paternal contribution, while necessarily making mothers better off and fathers worse off (Observation 1), may also make children worse off in this case. ${ }^{16}$

\section{Redistribution}

How does a balanced-budget lump-sum redistribution of income from husbands to their wives impact on the welfare of the different household members? Would such redistribution necessarily benefit mothers or their children? How do gender-specific differences in the valuation of contributions mediate the welfare consequences of redistribution? Analogously, how does a unit increase in communal provision funded by a lump-sum unit tax on either parent impact on intra-household allocation? I now proceed to address these issues. Evidently, one can also interpret my questions in terms of a situation where the state has some given amount, say, a dollar, and has to decide whether to transfer this amount to $\mathrm{M}$ or F directly as a lump-sum increment in market income, or, indirectly, as an additional dollar of children's goods.

I consider a lump-sum redistribution of income from husbands to wives that is small enough to leave both individuals contributory even after the redistribution. Thus, I focus on a marginal redistribution from an initial Nash equilibrium where both $\mathrm{M}$ and $\mathrm{F}$ contribute. I also consider a marginal rise in communal provision from such an equilibrium, funded by a lump-sum tax on either parent. ${ }^{17}$

First notice that, under the traditional assumption of equal valuation $\left(\theta_{M}=\tau_{M}=1\right)$, such redistributions fail to alter the equilibrium consumption bundle of any household member. The losing parent reduces his contribution by the amount lost, while the recipient's contribution increases by exactly this amount. The two effects thus cancel one another. ${ }^{18}$ But what happens when valuations are unequal?

It turns out that, contrary to conventional wisdom, there appears no conflict of interest between fathers and mothers. Instead, a stark conflict arises between parental interests and their children's welfare. A lump-sum redistribution from husbands to wives improves the well-being of children only if wives value their husbands' contributions more than their own. However, in that case, the redistribution

${ }^{16}$ Notice that (12) implies an exogenous reduction in $I_{k}$ will make children better off if (and only if) $\beta>\theta_{k}$. Of course, this case is irrelevant from a policy perspective, since an equivalent increase in communal contribution will always dominate an exogenous reduction in $I_{k}$ in terms of children's consumption.

17 A large enough redistribution would force $\mathrm{M}$ to turn non-contributory. Once that happens, further redistribution can only make both $\mathrm{F}$ and her children better off, while reducing the welfare of $\mathrm{M}$. Thus, it is the impact of redistributions in the intermediate range, which keep both $\mathrm{M}$ and $\mathrm{F}$ contributory, that is of substantive interest.

18 Specifically, when $\theta_{M}=1$, any such redistribution between $\mathrm{M}$ and $\mathrm{F}$ would have no effect on individual consumption. If $\tau_{k}=1$, any such rise in communal provision, funded by a lump-sum tax on parent $k$, would be likewise neutral. Both are examples of the well-known neutrality property of Cournot games of contribution to pure public goods. See Bergstrom, Blume and Varian (1986) and Cornes and Sandler (1996) for discussions. 
also necessarily reduces the private consumption (and welfare) of both parents. Conversely, if the redistribution improves the private consumption (or welfare) of mothers, it must also necessarily reduce the welfare of their children, but improve that of fathers. Furthermore, given over-valuation of parental contribution, any increase in communal provision, funded by a lump-sum tax on either parent, necessarily improves the consumption of children, while making both parents worse off. Thus, under normative over-valuation of parental contribution relative to communal contribution, from the children's perspective, a shift to communal provision necessarily dominates parental provision, while communal provision is the worst alternative from the perspective of either parent. The ranking is reversed when communal provision is over-valued. I formally summarize these findings in Proposition 1 below.

\section{Proposition 1. Let $A 1$ and $A 2$ hold.}

(i) Consider any lump-sum redistribution from $M$ to $F$ such that both parents remain contributory subsequent to the redistribution. Then the redistribution must increase the private consumption (and real income) of both parents, but reduce children's consumption, when $\theta_{M}>1$. Children's consumption will rise, but private consumption (and real income) of both parents fall, when $\theta_{M}<1$.

(ii) Consider any lump-sum redistribution from $\mathfrak{I}$ to $k \in\{M, F\}$ such that both parents remain contributory subsequent to the redistribution. When $\tau_{k}<1$, the redistribution must increase the private consumption (and real income) of both parents, but reduce children's consumption. Children's consumption will rise, but private consumption (and real income) of both parents fall, if $\tau_{k}>1$.

Proof: See the Appendix.

Intuitively, the basic mechanism driving these findings is the following. In response to a loss of one dollar to F, M is going to reduce his contribution to children's expenses by some amount. The lower the value of $\theta_{M}$, the lower the consequent net gain in real income to $\mathrm{F}$, and therefore, the lower the increase in her private consumption. The positive impact on public good provision by $\mathrm{F}$ is therefore greater, the lower the value of $\theta_{M}$. The lower the value of $\theta_{M}$, the greater the net loss in real income to M; consequently, the lower his private consumption, and thus, the lower his reduction in public good provision. Hence, the lump-sum redistribution from $\mathrm{M}$ to $\mathrm{F}$ will increase total (Nash equilibrium) public good provision when $\theta_{M}<1$. However, as already noted, the higher the valuation of M's contribution by F, i.e., the lower the value of $\theta_{M}$, the greater the loss imposed on $\mathrm{F}$ by a given cutback in contribution by M. When $\theta_{M}<1$, the net effect is a fall in F's private consumption (and welfare), despite (indeed, because of) an increase in total children's consumption, and despite F being better off in purely monetary 
terms. In this case, $\mathrm{M}$ is also worse off due to his low valuation of his wife's additional contribution, relative to his own. The consequences are reversed when $\theta_{M}>1$. The intuitive explanation when collective provision replaces parental provision, via a lump-sum tax on some parent, is analogous. Given under-valuation of parental provision, greater communal provision benefits children, at the cost of their parents. Greater collective provision makes parents better off, but children worse off, when parental provision is valued less than communal contribution. It is however difficult to find any intuitive reason for considering this case seriously as an empirical possibility, rather than a theoretical curiosum. Thus, in general, Proposition 1 points to a conflict between the interests of parents and those of their children. ${ }^{19}$

By Proposition 1, income redistribution moves the Nash equilibrium utility levels of both parents in the same direction. Thus, if parental utility levels in the non-cooperative equilibrium are modeled as the threat points in a cooperative bargaining set-up (Lundberg and Pollak (1993)), the impact of income redistribution on the intra-household distribution of consumption becomes indeterminate, without further (quite stringent and ad hoc) assumptions regarding parental preferences.

\section{An extension: communal contribution to parental private consumption}

Women (especially those below some (household) income or asset poverty threshold) sometimes receive direct private consumption support, in the form of commodity transfers, from the community. Typical examples in developing country contexts include provision of free or subsidized food, health and (adult) education facilities. What consequences would such provision have in my context? Suppose that the community can also provide a private consumption supplement, $P_{k}$ to parent $k$. In the spirit of my earlier analysis, the utility function can now be generalized to $u^{k}\left(x_{k}+\eta_{k} P_{k}, y_{k}+\theta_{k} y_{-k}+\tau_{k} T\right)$, where $\eta_{k} \in(0,1]$. If $\eta_{k}=1$, private consumption purchased from own income is perceived as identical to private consumption provided by the community (as in traditional analysis). In that case, so long as $\mathrm{F}$ spends a positive amount on her own private consumption, the commodity transfer is identical, in terms of its impact on equilibrium allocation, to an equivalent earning gain by her. However, when $\eta_{k}<1, k$ receives greater utility if a dollar of communally-provided private consumption is replaced by a dollar of private consumption purchased from her own earnings, even though, in material terms, her private consumption is identical. Notice that the budget constraint (1) can now be rewritten as:

19 The children themselves would however not perceive such a conflict if they internalize the same relative valuations for paternal, maternal and collective contributions as their parents. Unlike their parents, children's consumption and their perception of their own welfare would then move in opposite directions. Consequently, in policy evaluation, one has to make a choice between these two criteria. As already discussed, there is a persuasive case for overriding children's preferences in favor of the material consumption criterion (recall footnote 3). 


$$
\left(x_{k}+\eta_{k} P_{k}\right)+\left(y_{k}+\theta_{k} y_{-k}+\tau_{k} T\right)=\left[I_{k}+\eta_{k} P_{k}\right]+\theta_{k} y_{-k}+\tau_{k} T ;
$$

while the unconstrained demand functions (3) and (4) can be rewritten as:

$$
\begin{aligned}
& \bar{x}_{k} \equiv x_{k}+\eta_{k} P_{k}=\bar{X}^{k}\left(\left[I_{k}+\eta_{k} P_{k}\right]+\theta_{k} y_{-k}+\tau_{k} T\right), \\
& B_{k}=B^{k}\left(\left[I_{k}+\eta_{k} P_{k}\right]+\theta_{k} y_{-k}+\tau_{k} T\right) .
\end{aligned}
$$

It is easy to see, from (1'), (3'), (4') and (5), that, given A1-A2 and an interior solution to $k$ 's optimization problem, the following must hold. When $\eta_{F}<1$, a marginal increase in communal provision of F's private consumption, funded by a lump-sum tax on her, must necessarily reduce M's private consumption, while increasing total private consumption from all sources $\left(x_{F}+P_{F}\right)$ by $\mathrm{F}$. In real income terms, however, both parents must necessarily be worse off. Thus, $B_{M}, B_{F}, y_{F}$ must all fall, while $y_{M}$ must rise. Notice now that $\left[B_{M}+\left(1-\tau_{M}\right) T+\left(1-\theta_{M}\right) y_{F} \equiv y\right]$. It follows that $y$ must necessarily fall when $\theta_{M} \leq 1$ (i.e., $\theta_{F} \geq 1$ ). Total children's consumption may possibly (though not necessarily) fall even if $\theta_{M}>1$. For example, in the case with identical and homothetic preference discussed earlier, it can be shown that children's consumption will fall if (and only if), $\theta_{F}<\beta^{-1}$, where $\beta \in(0,1)$ is the preference parameter. ${ }^{20}$ It follows from Proposition 1 that, in general, it is Paretoinefficient to use resources raised from a lump-sum tax on $\mathrm{M}$ for providing communal consumption support to F. If the policy objective is to increase children's consumption, this objective can be best met by using the tax revenue to provide direct communal consumption support to children. If the policy objective is to increase women's private consumption, this can be met by a direct earnings redistribution from $\mathrm{M}$ to $\mathrm{F}$ when $\theta_{M}>1$, and, (somewhat paradoxically), by a reverse redistribution from $\mathrm{F}$ to $\mathrm{M}$ when $\theta_{M}<1$. In both cases, earnings redistribution makes $\mathrm{F}$ better off both in terms of private consumption and welfare. Communal support to F's private consumption instead of an earning increment to her does increase her private consumption, but reduces her welfare, i.e., makes her worse off in her own perception, when there is some cultural opprobrium attached to receiving communal 'charity'. ${ }^{21}$

\footnotetext{
20 This is easy to check in light of footnote 16 . Of course, a given redistribution from $\mathrm{M}$ to $\mathrm{F}$ will increase F's private consumption more if used to supplement private consumption rather than market earnings (when $\theta_{M}>1$ ) .

21 Such opprobrium may also be attached to receiving a direct cash hand out (e.g. a welfare payment), as opposed to an indirect market earning increment (say, through subsidized training, education or credit facilities, or general job quotas): the latter is more likely to be socially perceived as legitimately 'earned' than the former. Analogously, a voluntary cash transfer from $\mathrm{M}$ to $\mathrm{F}$ is not likely to be seen as F's 'earned', and thus 'own', income; whereas an equivalent increase in her market earnings brought about by the state, through an indirect, contingent and complicated process of generalized pro-female tax-subsidy intervention, is likely to be seen as so.
} 


\section{Concluding remarks}

An influential strand of the discourse on developmental policy emphasizes the importance of measures to redistribute income from husbands to wives. Sometimes the justification provided is their presumed beneficial impact on the welfare of mothers, at other times it is their presumed beneficial impact on the welfare of children. Typically there is a further presumption regarding congruence of interests between women and children, in opposition to those of men. Government offices purporting to look after the welfare of 'women and children' are a common sight in developing countries. As this paper has shown, none of these presumptions is beyond question: important caveats may in fact be in order in every case.

Expanding a theme initiated in Dasgupta (2001, 2000), I have shown that the impact of measures to redistribute income from fathers to mothers is critically contingent on structural features of a society. These structural features include internalized cultural norms that put differential emphases on paternal and maternal contributions to child-rearing. Specifically, redistribution towards mothers is likely to increase children's consumption if maternal contributions are valued less than paternal contributions. Intuitively, one expects this to obtain in societies that consider providing for children primarily a paternal responsibility. In such societies, however, the redistribution may reduce the personal consumption (and welfare) of mothers, despite their receiving income increments. Fathers may likewise be worse off. Conversely, redistribution towards mothers is likely to reduce the welfare of children in societies that valorize maternal contributions over paternal contributions. In such cases, mothers themselves are likely to achieve a personal consumption (and welfare) improvement from the redistribution. Ironically, so would fathers, despite their becoming financially worse off. There may thus exist, in either case, a 'parents or child' trade-off, instead of the standard 'mother and child' conflation. In determining whether to advocate redistribution from fathers to mothers, one has to: (i) clarify whether the intended beneficiaries are conceived primarily as the mothers themselves or their children, and (ii) identify the relative weights put on paternal and maternal contributions in the relevant cultural milieu.

I have also shown that, given social stigmatization of parental dependence on communal contribution to children's upkeep, greater communal provision of children's goods, funded by a lumpsum tax on parents, may expand children's consumption. Thus, in this case, greater communal provision may dominate parental provision from the children's perspective, while the opposite is true from the perspective of parents. Consequently, my results appear to question the logic of policy interventions that seek to transfer greater resources to mothers with the objective of improving the well-being of children.

The possibility of a conflict between the interests of parents and those of children, highlighted in this paper, evidently raises interesting questions regarding the political feasibility of pro-child interventions. My results suggest that politically popular redistribution proposals may sometimes be those that hurt children. Tax cuts for parents, funded by reduced state provision for children, are likely to 
be popular with parents, but may reduce children's consumption. Weakening of informal institutions of communal governance, such as tribal and clan councils, may likewise have a negative impact on children. Investigation of these questions is likely to prove useful. Application of the theoretical framework developed in this paper to specific policy contexts would appear to constitute another useful line of future research. Empirical investigations of the extent to which, in alternative cultural contexts, (i) a relative increase in maternal market earnings ‘crowds out' paternal contributions to children's expenses, and (ii) greater public contribution crowds out parental contributions, would also seem to be in order.

\section{Appendix}

\section{Proof of Observation 1.}

(i) Suppose a fall in $\theta_{F}$ does not increase $y_{F}$. Then $x_{F}$ cannot fall. By A1, given $\tau_{M}$, a fall in $\theta_{F}$ must reduce $\tau_{F}$. Hence, (noting (3)), by A2, $y_{M}$ must rise, and thus, $x_{M}$ must fall. This, in turn, by A1(i) and A2, implies that $B_{M} \equiv \theta_{F}{ }^{-1} B_{F}$ must fall, and thus, $B_{F}$ must fall. But then, by A2, $x_{F}$ must fall as well: a contradiction. Hence a fall in $\theta_{F}$ must increase $y_{F}$. It follows by A1(i) and A2 that $x_{M}$ must rise, and thus, $y_{M}$ must fall. It follows immediately from A2 (noting (7)) that maternal real income must fall, while paternal real income must rise.

(ii) First notice that, given $\theta_{F}$, any rise in $\tau_{M}$ must also increase $\tau_{F}$ (by A1). Without loss of generality, suppose $y_{M}$ does not fall. Then $x_{M}$ cannot rise; hence, by A2, $B_{M}$ cannot rise. But this in turn implies, by A2 (and noting (5)), $x_{F}$ cannot rise either. Hence $y_{F}$ cannot fall. But in that case, by A2, $x_{M}$ must rise: a contradiction. Hence, any rise in $\tau_{M}$ must raise private consumption of both parents, and thus, reduce children's consumption. A2 then implies parental real incomes must rise.

I shall prove Proposition 1 via three Lemmas, which I first state and prove.

Lemma 1: For any $i \in\{M, F, \mathfrak{I}\}, j \in\{M, F\}, i \neq j$, consider any lump-sum redistribution from $i$ to $j$ such that both $M$ and $F$ remain contributory subsequent to the redistribution. Let A1 and A2 hold. Then, in the post-redistribution Nash equilibrium, for all $k \in\{M, F\}$ :

(i) $\quad x_{k}$ will increase (decrease) if, and only if, $x_{-k}$ also increases (decreases);

(ii) $\quad x_{k}$ will increase (decrease) if, and only if, y decreases (increases); and

(iii) $\quad x_{k}$ will increase (decrease) if, and only if, $r_{k}$ also increases (decreases).

\section{Proof of Lemma 1.}


By A2, $x_{F}$ will increase (decrease) in the post-redistribution Nash equilibrium if and only if $B^{F}$ increases (decreases) as well. Noting (5) and A1(i), and using A2, the claim in part (i) follows.

(ii) Since $\left[y \equiv\left(I_{M}+I_{F}+T\right)-\left(x_{F}+x_{M}\right)\right]$, part (ii) is immediate from part (i).

(iii) Part (iii) follows from A2, the budget constraint (1) and the definition of real income (7).

Lemma 2: For any $k \in\{M, F\}$, consider any lump-sum redistribution from $-k$ to $k$ such that both $M$ and F remain contributory subsequent to the redistribution. Let $A 1$ and A2 hold. Then, in the post-redistribution Nash equilibrium, $x_{k}$ will increase (decrease) if, and only if, $\theta_{k}<(>) 1$.

\section{Proof of Lemma 2.}

Let $y_{k}^{*}, \hat{y}_{k}$ denote, respectively, the initial and post-redistribution contribution by $k$; let $R$ denote the magnitude of the redistribution from $-k$ to $k$. First suppose $x_{k}$ increases. Then, $\left[\hat{y}_{k}-R\right]<y_{k}^{*}$. Hence, $\left[I_{-k}+\theta_{-k} \hat{y}_{k}-R\right]<\left[I_{-k}+\theta_{-k} y_{k}^{*}\right]$ when $\theta_{-k} \leq 1$, i.e., $\theta_{k} \geq 1$. However, by Lemma 1(i) and A2, I have $\left[I_{-k}+\theta_{-k} \hat{y}_{k}-R\right]>\left[I_{-k}+\theta_{-k} y_{k}^{*}\right]$; hence $x_{k}$ will increase only if $\theta_{k}<1$. Analogously, one can show that $x_{k}$ will decrease only if $\theta_{k}>1$, and that $x_{k}$ will remain constant only if $\theta_{k}=1$.

Lemma 3: For all $k \in\{M, F\}$, consider any lump-sum redistribution from $\mathfrak{I}$ to $k$ such that both $M$ and F remain contributory subsequent to the redistribution. Let $A 1$ and A2 hold, and suppose $\tau_{k}<1$. Then, in the post-redistribution Nash equilibrium, $x_{k}$ must increase.

\section{Proof of Lemma 3.}

Let $y_{k}^{*}, \hat{y}_{k}$ denote, respectively, the initial and post-redistribution contribution by $k$; let $R$ denote the magnitude of the redistribution from $\mathfrak{I}$ to $k$. Suppose $x_{k}$ does not increase. Then, by Lemma 1(i), $x_{-k}$ cannot increase either, so that $\left[\hat{y}_{-k} \geq y_{-k}^{*}\right]$. Hence, for all $\tau_{k} \in(0,1)$, $\left[I_{k}+R+\theta_{k} \hat{y}_{-k}+\tau_{k}(T-R)\right]>\left[I_{k}+\theta_{k} y_{-k}^{*}+\tau_{k} T\right]$. Then, by A2, $x_{k}$ must rise: a contradiction. $\diamond$

\section{Proof of Proposition 1.}

Lemma 1 and Lemma 2 together yield part (i), while Lemma 1 and Lemma 3 together yield part (ii). $\diamond$ 


\section{References}

Andreoni, J. (1990): “Impure altruism and donations to public goods: a theory of warm-glow giving”, Economic Journal 100: 464-477.

Baland, J.-M. and Platteau, J.-P. (2003): “Economics of common property management regimes”, in K.G. Maler and J. Vincent (eds.), Handbook of Environmental Economics Volume 1, Amsterdam: Elsevier North-Holland.

Bergstrom, T.C., Blume, L. and Varian, H., (1986): “On the private provision of public goods”, Journal of Public Economics 29: 25-49.

Boserup, E. (1985): “Economic and demographic interrelationships in sub-Saharan Africa”, Population and Development Review 11: 383-397.

Breunig, R. and Dasgupta, I. (2005): “Do intra-household effects generate the food stamp cash-out puzzle?” American Journal of Agricultural Economics 87: 552-568.

Breunig, R. and Dasgupta, I. (2003): “Are people ashamed of paying with food stamps?” Journal of Agricultural Economics 54: 203-225.

Breunig, R. and Dasgupta, I. (2002): “A theoretical and empirical evaluation of the functional forms used to estimate the food expenditure equation of food stamp recipients: comment”, American Journal of Agricultural Economics 84: 1156-1160.

Caldwell, J. and Caldwell, P. (1978): "The achieved small family: early fertility transition in an African city”, Studies in Family Planning 9: 2-18.

Carter, M. and Katz, E. (1997): "Separate spheres and the conjugal contract: understanding the impact of gender-based development”, in L. Haddad, J. Hoddinott and H. Alderman (eds.), Intrahousehold Resource Allocation in Developing Countries; Baltimore: The Johns Hopkins University Press

Chen, Z. and Woolley, F. (2001): “A Cournot-Nash model of family decision-making”, Economic Journal 111: 722-48.

Cornes, R. and Sandler, T. (1996): The Theory of Externalities, Public Goods and Club Goods, 2nd edn. Cambridge: Cambridge University Press.

Cornes, R. and Sandler, T. (1994): “The Comparative Static Properties of the Impure Public Good Model”, Journal of Public Economics 54: 403-421.

Dasgupta, I. (2001): ‘Gender-biased redistribution and intra-household distribution’, European Economic Review 45: 1711-1722.

Dasgupta, I. (2000): ‘Women’s employment, intra-household bargaining, and distribution: a twosector analysis’, Oxford Economic Papers 52: 723-744

Dasgupta, I. and Kanbur, R. (2007a): ‘Community and class antagonism', Journal of Public Economics 91: 1816-1842. 
Dasgupta, I. and Kanbur, R. (2007b): “Should Egalitarians Expropriate Philanthropists?” mimeo, Cornell University.

Dasgupta, I. and Kanbur, R. (2005): “Community and Anti-Poverty Targeting”, Journal of Economic Inequality, 3: 281-302.

Fapohunda, E.R. and Todaro, M.P. (1988): "Family structure, implicit contracts and the demand for children in southern Nigeria”, Population and Development Review 14: 571-94.

Ihori, T. (1996): “International public goods and contribution productivity differentials”, Journal of Public Economics 61: 139-154.

Ihori, T. (1992): “Impure public goods and transfers in a three-agent model”, Journal of Public Economics 48: 385-401.

Kanbur, R. (1995): “Children and intra-household inequality: a theoretical analysis”, in K. Basu, P.K. Pattanaik and K. Suzumura (eds.) Choice, Welfare and Development: A Festschrift in Honour of Amartya K. Sen; New York: Oxford University Press.

Konrad, K. and Lommerud, K. (1995): “Family policy with non-cooperative families”, Scandinavian Journal of Economics 97: 581-601

Levedahl, J. (1995): “A theoretical and empirical evaluation of the functional forms used to estimate the food expenditure equation of food stamp recipients”, American Journal of Agricultural Economics 77: 960-68.

Lundberg, S. and Pollak, R.A. (1993): “Separate spheres bargaining and the marriage market”, Journal of Political Economy 101: 988-1010.

Lundberg, S., Pollak, R.A. and Wales, T. (1997): “Do husbands and wives pool their resources? Evidence from the United Kingdom Child Benefit”, Journal of Human Resources 32: 463-80

Moffitt, R. (1983): “An economic model of welfare stigma”, American Economic Review 73: 1023-35.

Ostrom, E. (1990): Governing the Commons: The Evolution of Institutions for Collective Action, New York: Cambridge University Press.

Udry, C. (1996): “Gender, agricultural production, and the theory of the household”, Journal of Political Economy 104: 1010-1046. 
